\title{
A SUPPLY CHAIN MANAGEMENT BASED CUSTOMER PREDICTION MODEL FOR GROCERY STORE
}

\author{
Jolly Rastogi \\ Assistant Professor, IET, Lucknow, Uttar Pradesh, India \\ Dr. Supriya Awasthi \\ Assistant Professor, Khwaja Moinuddin Chishti Language University, \\ Lucknow, Uttar Pradesh, India
}

\begin{abstract}
Management is now on the verge of a breakthrough in figuring out precisely how the interactions ultimately decide performance in the service sector between knowledge flows, resources, energy, human resources, and capital equipment. How these five concepts of flow interlock to be able to reinforce one another and to bring about switching and fluctuation should provide the grounds for predicting the emergence of actions, strategies, organizational types and investment choices. A principle of distribution management that recognized the interconnected complexities of organizational relationships as organizations are so intertwined. The expert argued that technological capabilities would affect the overall functionality of skills such as science, engineering, sales, and promotion. Illustrated phenomena use a laptop computer or perhaps computer simulation of order information flow along with the impact of its effect on development in addition to the general distribution functionality for each supply chain member, in addition to the entire supply chain application. A proposed customer forecasting model based on Machine Learning will be implemented to show the customer forecasting research work for the grocery store located in Lucknow, Uttar Pradesh, India. This research paper outlines the use, application and implementation of the Kernel-based Support Vector Machine for regression analysis. Also, it selects the best Kernel for the predicted model to be implemented.
\end{abstract}

Key words: Supply Chain Management, Machine Learning, Support Vector Machine, Artificial Neural Network, Grocery Store.

Cite this Article: Jolly Rastogi and Supriya Awasthi, A Supply Chain Management Based Customer Prediction Model for Grocery Store, International Journal of Management, 11(12), 2020, pp 798-809.

http://iaeme.com/Home/issue/IJM?Volume=11\&Issue=12 


\section{INTRODUCTION}

Today we have the basic requirements of a concept of the supply chain; let us move on to the differences between the supply chains of the manufacturing as opposed to the service business. Field expert says that will note four critical differences between the two sectors between terms of production, distribution, finished goods, as well as supply chain flows. For inputs, the big difference between service and manufacturing is the fact that the latter requires an input of physical labour (packaging, shipping, etc.) as well as the service business calls for labour feedback in the form of relationship building, or even manipulating information. Companies transfer material in logistics while no physical object is moved in the service industry. However, only information is exchanged via telephone, email, and more [1]. Some experts point out that modern software \& equipment is primarily used to accelerate the information process for the service industries. One of the main disparities between the two sectors is finished goods. A production process in manufacturing is, in fact, a raw material that has been wholly transformed whereas, in a service business, it is a service flow [2].

Nevertheless, in the optimization, both the manufacturing and service industries are unique but similar at the same time both of these industries are working to improve their operations, such as accelerating delivery or even reducing costs. By eliminating bottlenecks and finding much better prices on raw materials, companies are improving their profits. By developing much stronger partnerships to help where a service organization is not active, they boost their company and help remove virtual bottlenecks [3].

Service companies have different customers' operations needs. Businesses that manage or maybe fix things, business consulting, or maybe provide other services or healthcare usually have higher labour content reducing investment in machinery and plants because of this, the most significant asset of a service-based organization is their staff. It is not only the staff but also the contacts with many other organizations that are very important to a company's continued performance [4]. A service company will work diligently to ensure that staff, business associates and other people around the business are happy. The first job of entrepreneurship is to get the concept of a takeout company going. This particular company was fantastic at offering incentives for the staff on the floor to help keep them satisfied. It is necessary to keep the employees motivated through gift certificates, cash prizes and other things had been offered. This taking out chain knew those happy workers were translated into happy customers. Imagine a plan to encourage staff to stay satisfied with their work [5].

Companies have recently started to realize the advantages of communicating the integration and knowledge around the supply chain stakeholders. While such initiatives lessen forecast errors, they are not omnipresent, nor are they total and forecast errors still abound. Collaborative forecasting, as well as replenishment, enables an organization and its supplier firm to coordinate choices through the sharing of complicated decision support models and techniques, thereby enabling the incorporation of forecasting and performance schedules [6]. Nevertheless, in the absence of both collaborative forecasting and replenishment, companies are relegated to conventional forecasting as well as output scheduling. As a consequence, the needs of the company tend to fluctuate predictably even though the demand of the last client has a consistent pattern. Because of a significant bullwhip impact, forecasting the manufacturer's demand under these circumstances is getting a complicated process [7].

\section{PREDICTION}

Prediction is an old activity, which has recently become much more sophisticated. For a while, constant measures were noticed as well as extended into the future in time series information set, such as natural trends or perhaps cycles. Nevertheless, a mixture of time series, economic theory models as well as econometrics could be used today to create 
numerous predictions that could be interpreted jointly or even put together in sensible ways to make an excellent model. The element being projected is, in fact, an unpredictable random [8]. At first, attention was mainly oriented to the mean of this variable; later to the variance, and today to the entire marginal section. Pre-testing the knowledge to check for its necessary capabilities is now crucial. It has evolved contemporary methods such as co-integration. Equally important is the horizon from which the forecast is attempted, as are more extended prediction [9].

Besides, the issue of prediction assessment has been significantly established. Some predictions are straightforward to determine while others are more complicated, coming out of the Global Models. Governments, global agencies, exchange, or company will consider that such designs if pursued, might provide valuable assistance for their prediction activities or even their efforts to improve prediction accuracy. As a consequence, forecasting is a necessity in almost any operation [10]. However, because of the progress made by the investigation, the resources of forecasting in frequent business consumption continue to be primitive. Therefore, encouraging prediction technologies to support predictive analytics is considered a worthwhile undertaking as well as the goal of this research paper. Additionally, this kind of equipment may decrease anxiety as well as uncertainty characteristic of global trade. Connecting various business parameters that could change as well as influencing choices is very abundant that any credible efforts to run significant associations are needed by business owners around the world [11].

Prediction is studied across many disciplines, and many techniques have been created to make predictions based on historical details. We do not attempt to discuss all the different solutions with these. Still, we refer the audience to one of the numerous introductory texts explaining exponential smoothing, spectral studies, and neural networks, along with other conventional techniques, is an excellent introduction to several predictive strategies used in economic forecasting as well as modelling. The proliferation of methods is in part a sign that the very best means for just about any specific issue could count on numerous factors, such as the type and amount of available information, as well as the domain name attributes [12]. Most uses rely on evaluating approaches to decide by far the most appropriate approach for a specific problem, for instance, see applying prediction to the application or sales to predict electrical energy prices. The cost of the prediction method approach focuses on combining predictions made using strategies' differentiated energy sources as well as knowledge. Different techniques for merging predictions have been created, often driven by the question of merging the professional views. Predictions markets have recently turned out to be a favourite to aggregate details. Such approaches share specific roles with these industries, such as the use of logarithmic scoring rules to determine predictive quality [13].

\section{LITERATURE REVIEW}

Stable need planning, as well as sales forecasting, will provide a multitude of advantages across the supply chain. Precisely, it will help improve employee efficiency, reduce headcounts, reduce inventories, and stimulate stock flows, and increase sales and earnings. This research work expresses views on this critical supply chain activity from a selection of instructive perspectives. It comes with a framework for linking business plans as well as sales forecasts both vertically and horizontally with the group and in collaboration with the supply chain partners [14-16].

Demand forecasting is an essential component of supply chain preparation activities. Perhaps the most common technique for forecasting need in these companies includes the use of a computerized forecasting program to establish first forecasts as well as the corresponding judgmental aspect of the demand planners' forecasts, ostensibly to take into account unusual 
circumstances expected with the planning horizon. Making these modifications can involve a lot of management energy as well as time. However, they will improve accuracy and are, therefore, better than others in several types of features [17].

Authors [18] gathered information on over 60,000 forecasts and results from four supply chain businesses to explore this. On average, judgmental changes in three of the businesses increased accuracy.

Nevertheless, a thorough study found that while the comparatively more significant changes appeared to result in more general accuracy improvements, the smaller changes typically harmed accuracy. Positive adjustments, including an upward modification of the outlook, were less likely to enhance precision than imperfect adjustments. Besides, they were produced more often on the wrong path, suggesting a general bias toward trust. Designs to eradicate these kinds of biases were then produced. Based on both this statistical analysis and organizational observation, this work moves on to analyze techniques designed to improve the utility of judgmental changes directly [19].

Using artificial neural networks for the prediction approach is modelled by artificial intelligence methods. The consumer product causes the problems in forecasting the future need as well as the precise forecast In the overall performance of the artificial neural community a benefit in an ever-changing demand and business environment predicting a company making the right choices about manufacturing or inventory control. The prediction's learning algorithm is imposed to predict the time sequence in the future better. Simulated time-series information along with practical product sales information is used to predict the functionality of the recurrent neural networks, and this is due to the influence in list trading feature of a few aspects on the need for performance. Therefore, it was found that the artificial neural network strategy offers much more accurate forecasting [20-22] as the forecast period gets short.

This research work [23] assesses the effect of predicting premature order commitments and designs under the volatility of demand in a supply chain with one qualified manufacturer as well as four retailers. Personal computer simulation models were used to simulate the retailers' need for forecasting and inventory replenishment choices in addition to the producer's production choices under a bunch of need patterns as well as capacity tightness scenarios. This research study found early-order commitments to varying degrees compared to overall costs as well as service levels, since retailers and also the supplier, indicating that the advantages of early-order commitment could be exploited through a combination of forecasting designs, need patterns as well as tightness of availability. A bit of investigation on managing the political and organizational dimensions of producing as well as improving forecasts incorporate ways continues to be done in this research work.

Authors [24] look at the implementation of a supply chain planning process in a consumer Electronics Company, focusing on the predictive technique the operation revolves around. This model's examination focuses on the advancement of forecasting and how it mediates and accommodates the purposeful prejudices that could hinder the accuracy of forecasting. Authors [24] categorize the causes of purposeful bias into deliberate, motivated by misalignment of rewards as well as the attitude of power to the company, and unintentional, arising from blind spots in both knowledge and procedural. Authors [24] show that the forecasting process, combined with the supporting elicitation and information exchange systems of assumptions, is, in fact, able to cope with the possible political struggle, as well as the procedural and informational deficiencies. Authors [24] show that the development of an unbiased team in charge of dealing with the forecasting procedure, an approach that we distinguish from the next generation of forecasts, can adequately reinforce the political dimension to enable process improvements to be steered. Last but not least, the authors [24] 
discover that while a coordination process the appropriate tasks, responsibilities and roles, and the system can be created to address existing business functional and individual biases, the brand new coordination structure will, in turn, create brand new people as well as purposeful biases. In reality, the released concept of purposeful prejudices, the evaluation of the political dimension of the forecasting process, as well as the thinking of a coordination structure are brand new constructs to better understand the interface between various other features and control of operations.

Supply chains are simply business networks pooling their resources, as well as capabilities to deliver value to the end customer. Corporations are not in a position to own or manage entire supply chains. Modern logistics, as well as advancements in information technology, have created a worldwide market where companies can make the most of the ability to supply globally. Businesses have been so specialized and partnering with other companies around the world. These companies then have to gradually concentrate on logistics and the coordination of the supply chain. This sort of coordination is a significant business process at the moment. Modern Supply Chain Management (SCM) begins with the premise that supply chain participants are primarily interested in optimizing their own goals, and this self-serving emphasis typically results in inferior performance. Another way of thinking about this by considering a sequence of optimum regional policies does not yield a maximum response worldwide [25-27].

Author [28] summarizes it as follows when each section of a team tries to maximize its or perhaps its advantage, regardless of the effect on different other team members, the full strength may suffer. This kind of inefficiencies also creeps in when rational supply chain members organize their activities separately rather than coordinating. An accepted example of this inefficiency is the bullwhip effect. This particular effect refers to the tendency of replenishment orders to increase in variation as one travels from supplier to distributor up the supply chain. A disintegrated information flow mixed with skewed need info along with a lack of compliance with the replenishment rule results predictably in weak source chain dynamics. This form of lack of coordination could even overshadow the economic benefits as well as the specialization of size. With this review, authors [28] concentrate on supply control and use the outcome of the bullwhip as an extreme example of inefficiency in the supply chain. Authors [28] illustrate the organizational importance of the outcome of the bullwhip as well as the methodological problems which may support both supervisors and researchers.

\section{PROPOSED PREDICTION METHODOLOGY}

Indeed, one of SCM's leading roles in enhancing the accuracy of forecasts. Since complete effort may not be feasible, considering the feasibility of forecasting need in the absence of essential data from many other partners is necessary. The cause of the need distortion in the lengthy SCM simulation is actually due to the SCM participants' demand signal processing [29-30]. Based on projection, the need for signal processing means that each party at the SCM performs a bit of processing on the required signal, thus changing it before passing it to the subsequent member. As the demand signal of the end-customer moves up the SCM, it becomes ever more distorted, and this happens when the functionality of the need for signal processing is the same in all persons of the long SCM. For example, even though all members of the supply chain operations for a six-month trend to predict demand, bias will still occur. Figure 1 describes the predictive model process used to construct the proposed model based on machine learning techniques. 


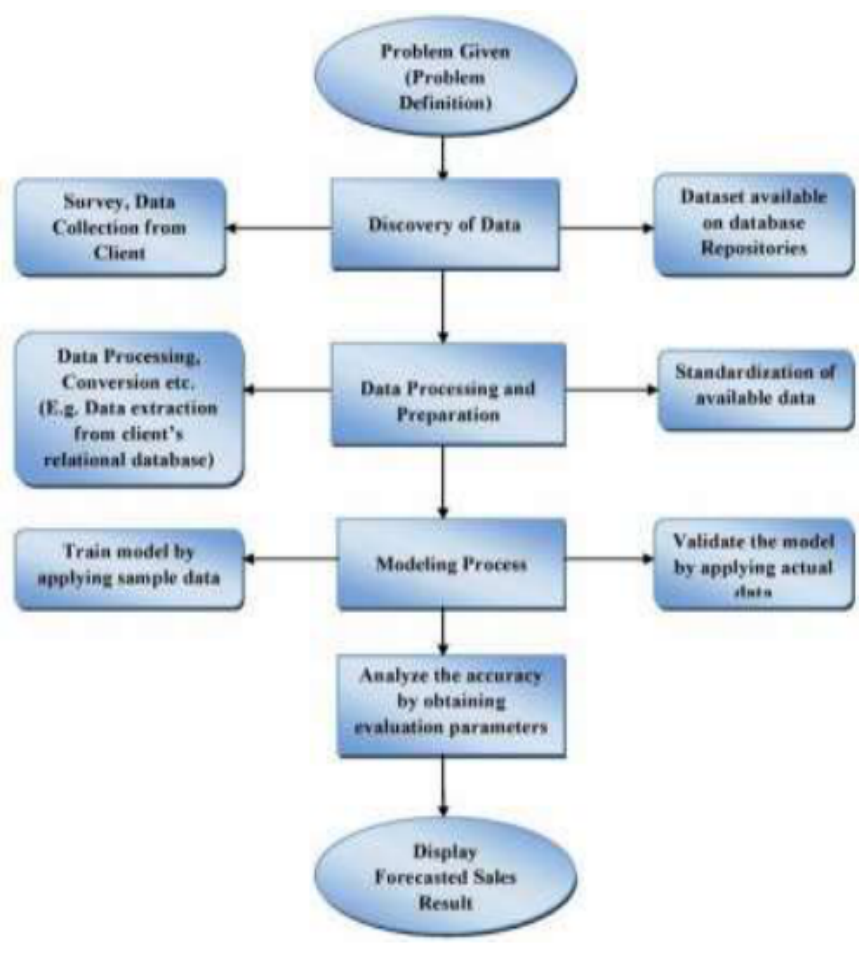

Figure 1 Machine Learning Based Prediction Model

The details of the implementation of the forecasting model are listed below:

- Evaluation of the problem domain and its description, as well as information needed for problem identification, is completed.

- We introduce the Data Discovery process after that. Data Discovery encompasses data collection from various available sources. These sources are defined as collecting data from survey data and collecting data from various grocery store stakeholders, as well as data from different available data repositories.

- Data collected in the preceding step is used for pre-processing of the data obtained. They are pre-processing of data used in the collected data to discard the outliers and noise present. Finally, specific data for the model is selected for further analysis. Change of information in a format which is essential, Data standardization may be part of this process.

- The additional step is projection process modelling. The sub-things of this phase are knowledge as well as validation.

- The design and training of the forecasting model are carried out based on the test dataset. After that, the prediction model is validated in this phase of education, and information and data learning are completed.

- The accuracy of the forecasting model is examined by obtaining parameters of evaluation including the Mean Absolute Percentage Error (MAPE), Mean Squared Error (MSE) and Mean Absolute Deviation (MAD) [31].

- Final estimated customer visits results are shown.

\section{DESIGN AND DEVELOPMENT OF PROPOSED PREDICTION FORECASTING MODEL}

Kernel-based Support Vector Machine (SVM) [32] technique is seen and defined in Figure 2. The kernel-based SVM methodology includes several steps like processing of the training 
dataset, choosing the Kernel-based on its capabilities and results, splitting the dataset into three sets, i.e. first set used for training purposes of the proposed model, the second set of data set used for validation purposes of the proposed model and third set of data set used for testing and performance analysis.

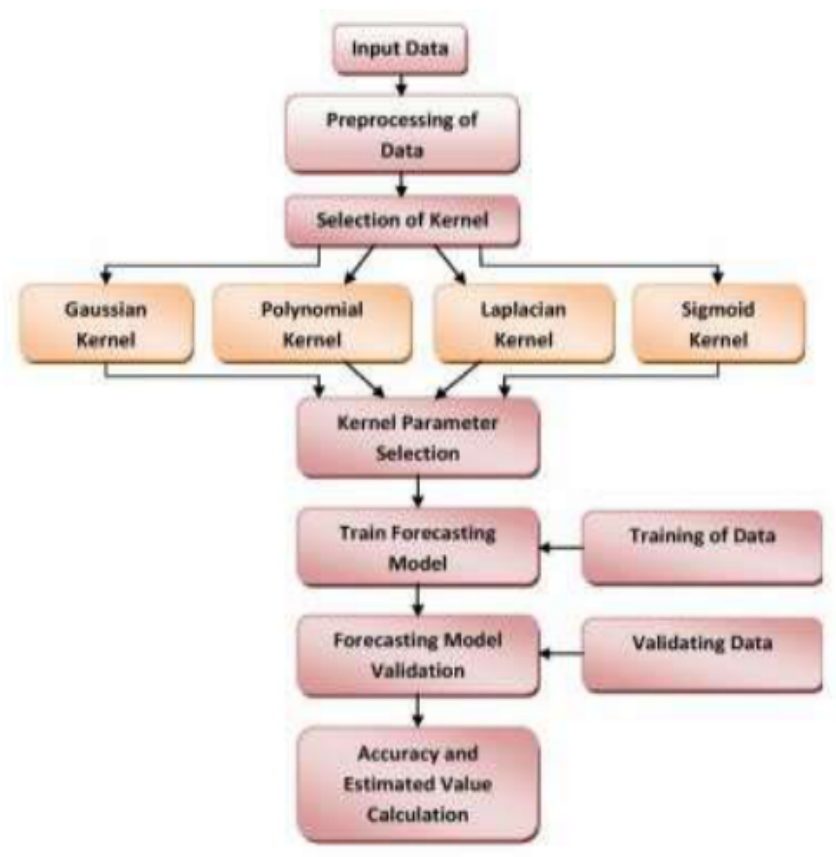

Figure 2 Flow of Kernel-Based SVM Technique

Kernel-based SVM technique which includes training of the proposed model, model validation test for parameter tuning of the model and last step includes testing of the proposed model. Such steps are set out as follows:

- Pre-processing of the collected dataset is performed after selecting the appropriate parameters and features and finally scaling in the range [-1, 1] and checking the dataset for possible outliers and removing these outliers for the dataset.

Kernel selection and regularization parameters are achieved by optimizing a configuration selection based on cross-validation.

- Appropriate kernel function that is selected by observing the solution space by applying the regression analysis to get the decision.

- We will construct and train the proposed training dataset model after choosing the correct values for the desired Kernel.

- Validation of model Forecasting is performed on model tuning validation data.

- We will select the excepted accuracy by proposing loss function and imposed a penalty to get the performance as per expectation.

- By implementing Mean Absolute Percentage Error (MAPE), Mean Squared Error (MSE), and Mean Absolute Deviation (MAD), the accuracy and performance of the proposed model are measured in the last step.

The process is applied in the development of the proposed model, i.e. the model training and the testing of the built model by using the Kernel-based SVM technique as developed and shown in Figure 2. 


\section{DATA PREPARATION}

A comprehensive collection of data is done through a survey. This survey is conducted at grocery stores located in Lucknow, Uttar Pradesh, India [33] and data obtained based on the actual customer's monthly, quarterly and annual visit to the grocery store located in Lucknow, Uttar Pradesh, India. The customers are broadly divided into three customer categories based on gender and age criteria. These categories are defined as Kid customers, Male and Female customers.

The proposed forecasting model was created and implemented with the assistance of the software Python [34] and Scikit-learn [35]. The computer hardware setup used with the Windows 10 operating system and RAM $8 \mathrm{~GB}$ is used to execute the experiments and to evaluate the effects of the proposed model forecasting. To evaluate the comparative results view. All the tests that were conducted were rerun to get the best possible precision.

The requirement of prediction is to conducts interviews and questionnaires in the grocery store's SCM process by inducing the relevant stakeholders into question. The observation during the interviews and questionnaires process indicates that there is an urgent need for an effective and efficient prediction system in the grocery store to improve the decision-making

process, optimize inventory storage management and finally improve the management of grocery store and its process.

\section{EVALUATION OF FORECASTING MODEL}

The prediction model performance evaluation and analysis are conducted based on the following evaluation criteria, i.e. Mean Absolute Percentage Error (MAPE), Mean Squared Error (MSE), and Mean Absolute Deviation (MAD). The model with the minimum MAPE value is selected during the performance assessment process of different constructed models since the minimum MAPE value indicates the best predictive performance for the prediction model [36]. Prediction error shows the value difference between the actual value and the predicted value given and determined by the forecast model for the selected prediction period [37].

Where $\mathrm{E}$ denotes the model's predicted error at duration $\mathrm{t}, \mathrm{y}$ is the real output value at duration $\mathrm{t}$ and $\mathrm{p}$ is the model's expected values during time $\mathrm{t}$ shown in equation 1.

$(t)=y(t)-p(t)$

MAPE defined by Equation 2, in which D is defined as the total number of data in the training dataset and equation.

$$
\text { MAPE }=\frac{\Gamma_{t=1}^{D} \frac{E(t)}{1(t)}}{D}
$$

MAD defined by Equation 3, where D is defined as the total number of data in the training set, and the equation as

$$
\mathrm{MAD}=\frac{\Gamma_{=1}^{D} E(t)}{D}
$$

MSE defined by Equation 4, in which D is defined as the total number of data in the training set and the equation as

$$
\mathrm{MSE}=\frac{\sum_{\mathrm{t}=1}^{D} E^{2}(\mathrm{t})}{D}
$$




\section{RESULTS}

Data relating to actual customer visits to the grocery store is collected from various grocery store billing counters, and this data is used to test the proposed model. The total number of customers, those have visited the grocery store based on monthly criteria, based on quarterly criteria and based on annual criteria for the chosen period, depending on the consumer and the consumer category needed to determine and measure the time duration chosen. Data expressed in terms of time series seen monthly, quarterly basis and annual basis for the period from August 2019 to July 2020 was obtained, analyzed and evaluated using the proposed model. For the same set of data with the same set of parameters for the proposed model, each proposed model has been analyzed and evaluated.

Results presented in a tabular manner, where Tables 1 shows the observed value of MAPE for Kernel-based SVM in comparison to other techniques and the value for Kernel-based SVM observed less as compared to the value of other techniques. Table 2 denotes the value of MAD, and we can observe that somehow similar value is seen for Mean MAD value.

Table 1: Mape Values for Male Customers

\begin{tabular}{|c|c|c|c|c|c|c|c|c|}
\hline Customers & $\begin{array}{c}\text { Kernel- } \\
\text { based } \\
\text { SVM }\end{array}$ & $\begin{array}{c}\text { Simple } \\
\text { Moving } \\
\text { Average }\end{array}$ & $\begin{array}{l}\text { Support } \\
\text { Vector } \\
\text { Machine }\end{array}$ & $\begin{array}{c}\text { Weighted } \\
\text { Moving } \\
\text { Average }\end{array}$ & $\begin{array}{c}\text { Artificial } \\
\text { Neural } \\
\text { Network }\end{array}$ & $\begin{array}{c}\text { Exponential } \\
\text { Smoothing }\end{array}$ & $\begin{array}{c}\text { Naïve } \\
\text { Bayes }\end{array}$ & $\begin{array}{c}\text { Adaptive } \\
\text { Rate } \\
\text { Smoothing }\end{array}$ \\
\hline 1 & 0.094 & 0.092 & 0.076 & 0.084 & 0.099 & 0.097 & 0.081 & 0.097 \\
\hline 2 & 0.071 & 0.086 & 0.081 & 0.088 & 0.077 & 0.074 & 0.067 & 0.096 \\
\hline 3 & 0.090 & 0.097 & 0.098 & 0.098 & 0.098 & 0.098 & 0.097 & 0.091 \\
\hline 4 & 0.085 & 0.092 & 0.091 & 0.092 & 0.092 & 0.090 & 0.091 & 0.093 \\
\hline 5 & 0.076 & 0.091 & 0.089 & 0.088 & 0.074 & 0.085 & 0.087 & 0.095 \\
\hline Average & 0.0832 & 0.0916 & 0.087 & 0.09 & 0.088 & 0.0882 & 0.0846 & 0.0944 \\
\hline
\end{tabular}

Table 2 shows that except in some cases, the calculated value of MAD in Kernel-based SVM is less as compared to other applied methods. Table 3 presents the performance of different techniques in terms of error generated for accurate calculation. These errors calculate for in terms of MAPE, MAD and MSE for test data and based on the results of test data. We are predicting customer visit in grocery store based on the category of the customers. The calculated results of each technique shown in Table 3 and the desired results for each grocery store customer are marked for desired performance evaluation. For representation and reference criteria, the calculated values of MAPE, MAD and Mean MSE are shown for Male customers.

Table 2: Mad Values for Male Customers

\begin{tabular}{|c|c|c|c|c|c|c|c|c|}
\hline Customer & $\begin{array}{c}\text { Kernel- } \\
\text { based } \\
\text { SVM }\end{array}$ & $\begin{array}{c}\text { Simple } \\
\text { Moving } \\
\text { Average }\end{array}$ & $\begin{array}{c}\text { Support } \\
\text { Vector } \\
\text { Machine }\end{array}$ & $\begin{array}{c}\text { Weighted } \\
\text { Moving } \\
\text { Average }\end{array}$ & $\begin{array}{c}\text { Artificial } \\
\text { Neural } \\
\text { Network }\end{array}$ & $\begin{array}{c}\text { Exponential } \\
\text { Smoothing }\end{array}$ & $\begin{array}{c}\text { Naïve } \\
\text { Bayes }\end{array}$ & $\begin{array}{c}\text { Adaptive } \\
\text { Rate } \\
\text { Smoothing }\end{array}$ \\
\hline 1 & 78 & 113 & 81 & 129 & 101 & 133 & 110 & 130 \\
\hline 2 & 73 & 123 & 79 & 130 & 90 & 127 & 105 & 129 \\
\hline 3 & 88 & 115 & 91 & 126 & 84 & 126 & 108 & 122 \\
\hline 4 & 80 & 99 & 84 & 95 & 89 & 88 & 101 & 108 \\
\hline 5 & 81 & 104 & 82 & 109 & 87 & 109 & 90 & 118 \\
\hline Average & 80 & 110.8 & 83.4 & 117.8 & 90.2 & 116.6 & 102.8 & 121.4 \\
\hline
\end{tabular}

A per the Table 3, the calculated value of MSE for Kernel-based SVM is less as compared to rest classical methods as well as less as compared to the artificial neural network, but an exception exists for some cases. The calculated values are opposing in a few customers. The average value of error levels of different techniques is indicating the dominance in terms of performance of the applied Kernel-based SVM model in comparison to the artificial neural network and the rest of the values of the classical method. Three error calculation methods, 
i.e. MAPE, MAD and MSE, indicates about the performance and ability of the Kernelbased SVM forecasting model for predicting the best and desired results.

Table 3: MSE Values for Male Customers

\begin{tabular}{|c|c|c|c|c|c|c|c|c|}
\hline Customer & $\begin{array}{c}\text { Kernel- } \\
\text { based } \\
\text { SVM }\end{array}$ & $\begin{array}{c}\text { Simple } \\
\text { Moving } \\
\text { Average }\end{array}$ & $\begin{array}{c}\text { Support } \\
\text { Vector } \\
\text { Machine }\end{array}$ & $\begin{array}{c}\text { Weighted } \\
\text { Moving } \\
\text { Average }\end{array}$ & $\begin{array}{c}\text { Artificial } \\
\text { Neural } \\
\text { Network }\end{array}$ & $\begin{array}{c}\text { Exponential } \\
\text { Smoothing }\end{array}$ & $\begin{array}{c}\text { Naïve } \\
\text { Bayes }\end{array}$ & $\begin{array}{c}\text { Adaptive } \\
\text { Rate } \\
\text { Smoothing }\end{array}$ \\
\hline 1 & 148 & 178 & 156 & 295 & 162 & 261 & 185 & 189 \\
\hline 2 & 106 & 196 & 121 & 276 & 130 & 244 & 168 & 227 \\
\hline 3 & 144 & 195 & 142 & 280 & 154 & 247 & 181 & 220 \\
\hline 4 & 142 & 192 & 151 & 215 & 149 & 252 & 142 & 229 \\
\hline 5 & 166 & 193 & 171 & 236 & 160 & 285 & 191 & 197 \\
\hline Average & 141.2 & 190.8 & 148.2 & 260.4 & 151 & 205.6 & 173.4 & 212.4 \\
\hline
\end{tabular}

\section{CONCLUSION}

In the study and analysis of this research paper, we have found that Kernel-based SVM showed best results as compared to other applied techniques. Other method shows less accuracy for different accuracy calculation methods, and criteria, i.e. MAPE, MAD and MSE. Kernel-based SVM showed a shorter time to learn and shows much better consistency as well as produces better results that are correct in comparison to other applied techniques because we have optimized threshold functions in a better way. Although artificial neural network provides better results in case amounts of iterations are more and showed some improvements in prediction errors. In machine learning, pre-processing as well as cleaning of the dataset is a crucial process in enhancing the performance of applied techniques just before applying and implementing the model. Accurate knowledge, as well as the solution of the problem domain, is needed before selecting a strategy and implementing technique to anticipate dataset, as various prediction techniques are available, but as per the requirement of the problem domain. Thorough cleaning of dataset and pre-processing of time series related dataset, we can improve the effectiveness and efficiency of the proposed model. It has been found that each forecasting design has its significance; one could be utilized for specific issue and problem; however, not for all problems and domains. The appropriate prediction design which can provide the desired solution for the problem domain must be selected, and detailed understanding of the knowledge of the problem domain can be advantageous.

\section{SOURCE OF FUNDING: SELF}

Conflict of Interest: None

\section{REFERENCES}

[1] Presutti Jr, W. D. (2003). Supply management and e-procurement: creating value added in the supply chain. Industrial marketing management, 32(3), 219-226.

[2] Ettlie, J. E., \& Rosenthal, S. R. (2011). Service versus manufacturing innovation. Journal of product innovation management, 28(2), 285-299.

[3] Berk, J. (2010). Cost reduction and optimization for manufacturing and industrial companies (Vol. 2). John Wiley \& Sons.

[4] Al-Sehali, S. (2000). The factors that affect the implementation of enterprise resource planning (ERP) in the international Arab Gulf states and United States companies with special emphasis on SAP software.

[5] Schonberger, R. (1990). Building a chain of customers: Linking business functions to create the world class company. Simon and Schuster. 
[6] Millar, M. (2015). Global Supply Chain Ecosystems: Strategies for competitive advantage in a complex, connected world. Kogan Page Publishers.

[7] Carré, F., Tilly, C., Van Klaveren, M., \& Voss-Dahm, D. (2010). Retail jobs in comparative perspective. Low-wage work in the wealthy world, 211-268.

[8] Conway, A. J. (1998). Time series, neural networks and the future of the Sun. New Astronomy Reviews, 42(5), 343-394.

[9] Petropoulos, F., Kourentzes, N., Nikolopoulos, K., \& Siemsen, E. (2018). Judgmental selection of forecasting models. Journal of Operations Management, 60, 34-46.

[10] Haas, E. B. (2018). When knowledge is power: Three models of change in international organizations (Vol. 22). University of California Press.

[11] Martino, J. P. (1993). Technological forecasting for decision making. McGraw-Hill, Inc..

[12] Rescher, N. (1998). Predicting the future: An introduction to the theory of forecasting. SUNY press.

[13] Sherden, W. A. (1999). The fortune sellers: The big business of buying and selling predictions. John Wiley \& Sons.

[14] Mentzer, J. T., \& Moon, M. A. (2004). Sales forecasting management: a demand management approach. Sage Publications.

[15] Van Landeghem, H., \& Vanmaele, H. (2002). Robust planning: a new paradigm for demand chain planning. Journal of operations management, 20(6), 769-783.

[16] Lovell, M. C. (1962). Buffer stocks, sales expectations, and stability: A multi-sector analysis of the inventory cycle. Econometric: Journal of the Econometric Society, 267-296.

[17] Makridakis, S., \& Wheelwright, S. C. (1977). Forecasting: issues \& challenges for marketing management. Journal of Marketing, 41(4), 24-38.

[18] Simchi-Levi, D., Kaminsky, P., \& Simchi-Levi, E. (2004). Managing the Supply Chain: Definitive Guide. Tata McGraw-Hill Education.

[19] Daganzo, C. (2014). Multinomial probit: the theory and its application to demand forecasting. Elsevier.

[20] Yousefi, M., Yousefi, M., \& Ferreira, R. P. M. (1998). A Review on the Application of Neural Networks for Decreasing Bullwhip Effect in Supply Chain. neural networks, 6.

[21] Özgen, C. (2011). Evaluation of performance and optimum valve settings for pressure management using forecasted daily demand curves by artificial neural networks (Doctoral dissertation, Doctoral dissertation, Middle East Technical University).

[22] PRO, U. E. Weather Prediction through Sentiment Analysis on Twitter and MultiDimensional Data.

[23] Wikner, J., Towill, D. R., \& Naim, M. (1991). Smoothing supply chain dynamics. International Journal of Production Economics, 22(3), 231-248.

[24] Kiekintveld, C., Miller, J., Jordan, P. R., Callender, L. F., \& Wellman, M. P. (2009). Forecasting market prices in a supply chain game. Electronic Commerce Research and Applications, 8(2), 63-77.

[25] Simchi-Levi, D., Kaminsky, P., Simchi-Levi, E., \& Shankar, R. (2008). Designing and managing the supply chain: concepts, strategies and case studies. Tata McGraw-Hill Education.

[26] Handfield, R. B., \& Nichols, E. L. (2002). Supply chain redesign: Transforming supply chains into integrated value systems. Ft Press. 
[27] Morgan, C. (2004). Structure, speed and salience: performance measurement in the supply chain. Business process management journal.

[28] Waters, D. (2011). Supply chain risk management: vulnerability and resilience in logistics. Kogan Page Publishers.

[29] Småros, J. (2007). Forecasting collaboration in the European grocery sector: Observations from a case study. Journal of Operations Management, 25(3), 702-716.

[30] Pati, N., Sundram, V. P. K., Chandran, V. G. R., \& Bhatti, M. A. (2016). Supply chain practices and performance: the indirect effects of supply chain integration. Benchmarking: An International Journal.

[31] Halimawan, A. A., \& Sukarno, S. Stock Price Forecasting Accuracy Analysis using Mean Absolut Deviation (MAD) and Mean Absolute Percentage Error (MAPE) on Smoothing Moving Average and Exponential Moving Average Indicator (Empirical Study 10 LQ 45 Stock with Largest Capitalization from pe. Indonesian Journal of Business Administration, 2(13), 68283.

[32] Zhang, Y., Fu, P., Liu, W., \& Chen, G. (2014). Imbalanced data classification based on scaling kernel-based support vector machine. Neural Computing and Applications, 25(3-4), 927-935.

[33] Chauhan, S. K., \& Kamboj, R. S. (2013). A study on the consumer perception towards private label brands with special reference to big bazaar, lucknow. International Journal of Technical Research and Applications, 1(3), 80-84.

[34] VanderPlas, J. (2016). Python data science handbook: Essential tools for working with data. " O'Reilly Media, Inc.".

[35] Géron, A. (2019). Hands-on machine learning with Scikit-Learn, Keras, and TensorFlow: Concepts, tools, and techniques to build intelligent systems. O'Reilly Media.

[36] Tofallis, C. (2015). A better measure of relative prediction accuracy for model selection and model estimation. Journal of the Operational Research Society, 66(8), 1352-1362.

[37] Ghiassi, M., Saidane, H., \& Zimbra, D. K. (2005). A dynamic artificial neural network model for forecasting time series events. International Journal of Forecasting, 21(2), 341-362. 